\title{
The influence of 5000 year-old and younger glacial mass variability on present-day crustal rebound in the Antarctic Peninsula
}

\author{
Erik R. Ivins ${ }^{1}$, Carol A. Raymond ${ }^{1}$, and Thomas S. James ${ }^{2}$ \\ ${ }^{1}$ Jet Propulsion Laboratory, California Institute of Technology, U.S.A. \\ ${ }^{2}$ Geological Survey of Canada, Sidney, British Columbia, Canada
}

(Received December 22, 1999; Revised June 19, 2000; Accepted June 20, 2000)

\begin{abstract}
Assessment of Antarctic rebound is complicated by two issues: (1) The total ice volume at Last Glacial Maximum is contentious, with estimates ranging from just a few meters to several tens of meters of equivalent eustatic sea level rise. (2) The late-Holocene mass budget is also uncertain. Space-based geodesy may provide important data in the coming years for estimating the recent ice mass balance state of Antarctica. Toward this end, GPS has an important role for isolating the solid earth movements that are associated with postglacial rebound. Here we provide numerical examples of vertical motions that are predicted by coupling realistic glacial load histories to 20th century ice mass imbalance estimates for the Antarctic Peninsula. The main complexity revealed by these examples is the striking difference among predictions that have an oscillatory mass change during the last 5000 to 50 years, as opposed to those having a continuous (non-oscillatory) mass drawdown of the grounded ice sheet.
\end{abstract}

\section{Introduction}

Global Positioning System (GPS) satellite geodesy has emerged during the last decade as a method of determining present-day deformation of the earth's crust at precisions of $1-3 \mathrm{~mm}$ in the horizontal and to within $10 \mathrm{~mm}$ in the vertical (Herring, 1999). Measurable changes in tilt and gravity accompany slow viscous rebound of bedrock once buried beneath the great ice sheets of the northern hemisphere that disintegrated from their Last Glacial Maximum (LGM) some 21 to 8 thousand years ago. GPS measurement of the pattern and rate of vertical crustal motion in Fennoscandia is now unfolding at a rapid pace (Scherneck et al., 1998). Efforts are now underway to make similar measurements on Antarctic bedrock (Tregoning et al., 1999; Raymond et al., 1999).

One of the main themes of current glaciological study in Antarctica is to unravel the mass history of the great ice sheet during the past 100,000 years, as this would provide a key parameter for the study of global paleoclimatology and paleoceanography. Significant progress has been made in the past decade, primarily fueled by new analyses of ice core data, datable volcanic-ice deposits and new terrestrial moraine and marine sediment chronologies (e.g., Bentley and Anderson, 1998; Ingólfsson et al., 1998). In terms of measuring the present-day glacioisostatic motions of the crust, a major challenge for numerical modelers is to account for the changes that occur during the past several thousand years since it is likely that the ice sheet has well-insulated internal dynamics, with a relatively slow response to external climatological forcing (Jòhannesson et al., 1989). Far-field relative sea level data may also provide evidence for a prolonged Antarctic ice sheet evolution over the past four thousand years (Okuno and

Copy right (c) The Society of Geomagnetism and Earth, Planetary and Space Sciences (SGEPSS); The Seismological Society of Japan; The Volcanological Society of Japan; The Geodetic Society of Japan; The Japanese Society for Planetary Sciences.
Nakada, 1998). The situation, however, may be rather complicated in coastal regions where changes in moisture flux and oceanic thermal conditions occur on both decadal and centennial time scales, thus influencing shorter time-scale ice mass budgets.

Several facts motivate a study of the glacial isostasy of the Antarctic Peninsula. First, a geodetic project directed by the Scientific Committee on Antarctic Research (SCAR) has retrieved several years of regional epoch campaign data (Dietrich et al., 2001). Secondly, the geographic setting of the Peninsula renders it more vulnerable to fluctuations in climate and precipitation than elsewhere in Antarctica. Finally, like the glacial geology that dominates West Antarctica, the region has clear evidence of a more expansive ice sheet during the last $35 \mathrm{kyr} \mathrm{BP}$ and, as such, several of the issues addressed in this study also bear upon our understanding of continent-wide Antarctic glacial isostasy. Using numerical experiments we show how some contrasting, yet realistic, scenarios for mass evolution over the past 5 kyr may affect future interpretation of secular trends in vertical GPS height measurements taken over the course of half a decade, or longer, in the Antarctic Peninsula. Striking contrasts are discovered among models that exhibit mass oscillations into the present millennium as these may exhibit a forced viscoelastic wave-like structure. In marked contrast, it will be shown that models having a continuous mass drawdown throughout the Holocene, with no oscillation, produce a more predictable pattern of uplift at present-day.

\section{Past and Present Ice Mass Changes}

Two computations set the stage for comparisons to examples of isostatic response to Holocene ice load evolution. First, a calculation of vertical uplift at present-day is given for deglaciation from LGM with no mid- to late-Holocene evolution. Secondly, a case for purely elastic isostasy is com- 
puted that is driven by a plausible present-day mass loss rate of $\dot{M}_{\mathrm{pd}}=-48 \mathrm{Gt} / \mathrm{yr}$. This value of present-day deglaciation is assumed operative for the last 150 years in all subsequent computations for the purposes of comparison. The details of mid- to late-Holocene ice mass evolution in the Peninsula region are largely unconstrained. Consequently, three end member cases of Holocene evolution are considered: (1) a case in which 4 glacial maxima are achieved within the last 4 kyr BP, (2) a case in which a slow ice build up proceeds over 4500 years to $1850 \mathrm{AD}$, and, finally, (3) a case in which a relatively small LGM load slowly builds up until $18 \mathrm{kyr}$ $\mathrm{BP}$, deglaciates by $80 \%$ until $5.5 \mathrm{kyr} \mathrm{BP}$, and then slowly and continuously dissipates throughout the remainder of the Holocene until 1850 AD. The theoretical model is described by Ivins and James (1999) and assumes an elastic lithosphere over an incompressible Maxwell half-space.

\subsection{Rebound from LGM}

Our knowledge of the past and present mass balance state of the Antarctic Peninsula is, unfortunately, rather limited. There is, however, clear evidence for periodic retreat and advance of glacier systems north of $65^{\circ} \mathrm{S}$ (e.g., Björck et al., 1996) and a large body of evidence now confirms that a more massive ice sheet was grounded to the continental shelf during the Last Glacial Maximum (Payne et al., 1989; Bentley and Anderson, 1998). A detailed discussion of this evidence is beyond the scope of the present paper. However, following a recent summary by Ingólfsson et al. (1998), Fig. 1 shows the locations of dated terrestrial and marine carbon deposits used

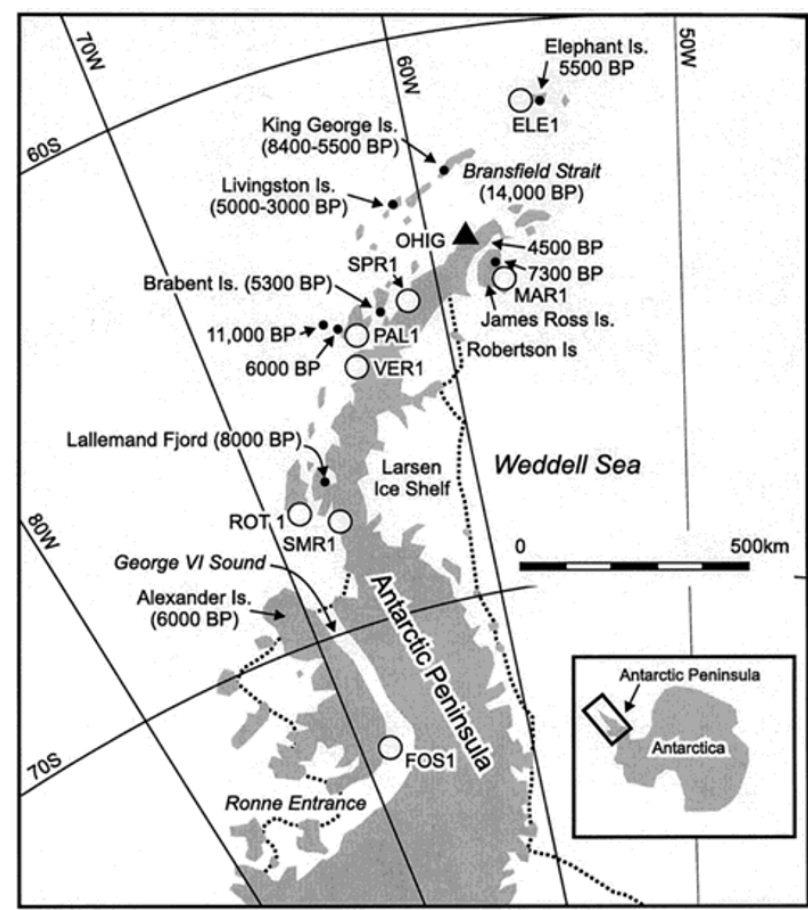

Fig. 1. Map of the Antarctic Peninsula. Locations of radiometric carbon dates that provide minimum ages for glacial retreat from LGM, as summarized by Ingólfsson et al. (1998), are indicated. Eight of the 17 SCAR GPS sites (Dietrich et al., 2001) and the permanently operating IGS station (O'Higgins) are shown as large solid dots and solid triangle, respectively. The complete SCAR network is shown at the website http: / / www . tu-dresden.de/ipg/tpgsc98 . html. (Adapted from Ingólfsson et al., 1998). to infer bounds on the spatiotemporal retreat of the LGM ice sheet margin. Here we employ an ice load history modified after models of Payne et al. (1989) and Denton et al. (1991). James and Ivins (1998) constructed a surface load for the entire Antarctic ice sheet, termed the D91 model, in which deglaciation from LGM was assumed to begin at $12 \mathrm{kyr}$ and terminate at $5 \mathrm{kyr}$ BP. The rather uncertain timing was set by far-field analyses of global paleoshorelines (Peltier, 1994). The total Antarctic contribution to postglacial eustatic sea level rise (e.s.l.r) from the previous D91 model was $24.5 \mathrm{~m}$.

Figure 2 shows a map of the predicted rate of present-day rebound for the Antarctic Peninsula using a disc-load modified from D91. The modifications follow a regional retreat history developed in the numerical simulation of Payne et al. (1989). The relatively coarse disc-gridding is shown in Fig. 2. Retreat from LGM is assumed to initiate at 14.0 kyr BP and terminate at $5.5 \mathrm{kyr}$ BP, largely consistent with moraine data (Clapperton and Sugden, 1988; Clapperton, 1990). The dates older than 6 kyr BP shown in Fig. 1 correspond to the recession from LGM. Younger dates may correspond to glacial readvances or to prolonged deglaciation (Clapperton, 1990; Ingólfsson et al., 1998). The D91 model was also reduced in total size to an e.s.l.r. of 20 meters. For computing the result shown in Fig. 2 the deglaciating discs cover the entire Antarctic continent. The predictions for present-day uplift rates are affected by the assumed value of the mantle viscosity. For example, along the southernmost coastline of Alexander Is. (see Fig. 1) the predicted uplift rate with a viscosity, $\eta=4 \times 10^{20} \mathrm{~Pa} \mathrm{~s}$, and lithospheric thickness, $h=70 \mathrm{~km}$, is 1.5 to $2.5 \mathrm{~mm} / \mathrm{yr}$ (see Fig. 2). In contrast, computational results (not shown here) for a mantle viscosity of $\eta=10^{21} \mathrm{~Pa} \mathrm{~s}$ and thicker lithosphere, $h=120$ $\mathrm{km}$, predict a rate of $6-9 \mathrm{~mm} / \mathrm{yr}$ at this same location. (Also see James and Ivins (1998), figure 13a, for computational

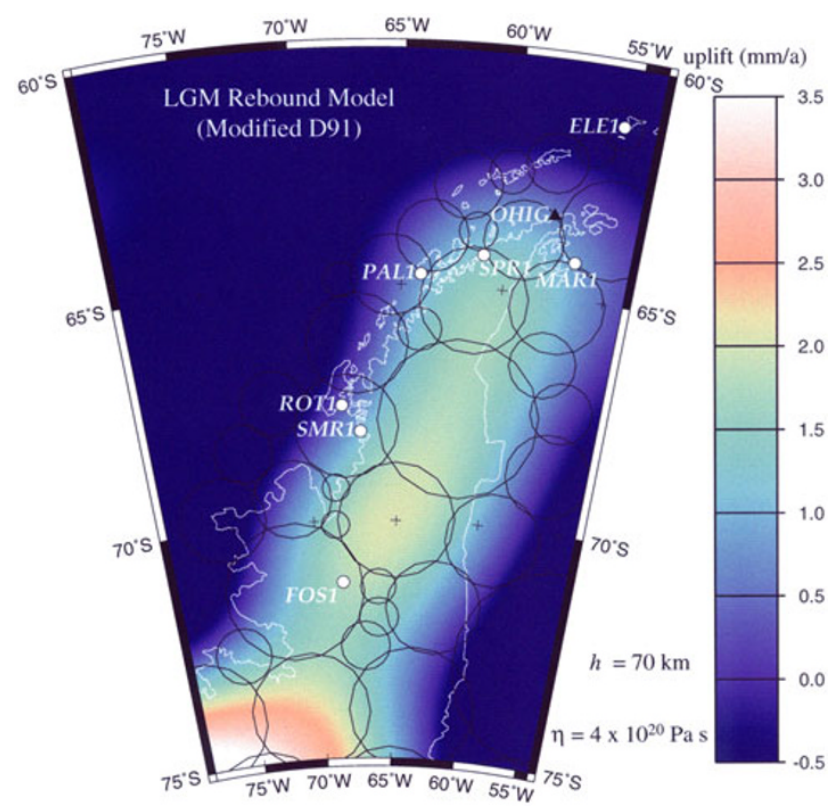

Fig. 2. Uplift rate, $\dot{w}$, in $\mathrm{mm} / \mathrm{yr}$ predicted from a continent-wide model of Antarctic deglaciation. The load model terminates evolution at 5.5 kyr BP. The load is modified from 'D91' of James and Ivins (1998) as discussed in the text. 
results for the unmodified D91 load, upper mantle viscosity, $\eta=10^{21} \mathrm{~Pa} \mathrm{~s}$ and $h=120 \mathrm{~km}$ ). Additionally, we computed the uplift rates for the modified D91 load with $h=50 \mathrm{~km}$ and $\eta=1.5 \times 10^{20} \mathrm{~Pa} \mathrm{~s}$, and in this case the predicted uplift rates reduce to the level of $0.1 \mathrm{~mm} / \mathrm{yr}$. It is important to consider reduced viscosity and thinner lithosphere due to the late Cenozoic tectonics of the Antarctic Peninsula. In particular, the mantle environment has absorbed a series of subducted ridge segments during the past 45 to $6 \mathrm{Myr}$ BP (Barker, 1982; Hole et al., 1991; Scarrow et al., 1998). However, presentday rifting is limited to crust well north of Alexander Is. (Bell and King, 1998). Consequently, solid earth rheology might be stronger than in analogous Neogene arc-related tectonic settings such as in southern British Columbia where viscosity and lithospheric thickness have been upper bounded at $\eta<10^{20} \mathrm{~Pa} \mathrm{~s}$ and $h<50 \mathrm{~km}$, respectively (James et al., 2000). We note that Studinger and Miller (1999) have estimated an effective elastic flexural thickness of $35 \mathrm{~km}$ for the lithosphere at the inner margins of the Weddell Sea.

\subsection{Mid-Holocene to present-day response}

Analyses of atmospheric energy and moisture transport indicate that the Antarctic Peninsula and environs are susceptible to extreme precipitation conditions (Cullather et al., 1998; Genthon and Krinner, 1998). It is estimated that the Peninsula receives roughly $25 \%$ of the total Antarctic mean annual surface accumulation, while accounting for only $6.8 \%$ of the total Antarctic ice sheet surface area (Drewry and Morris, 1992). The present mass flux of regional glacier systems into the oceans may be substantial and non-steady, possibly as evidenced by the recent breakup of the Larsen Ice Shelf near Robertson Island along the eastern flanks of

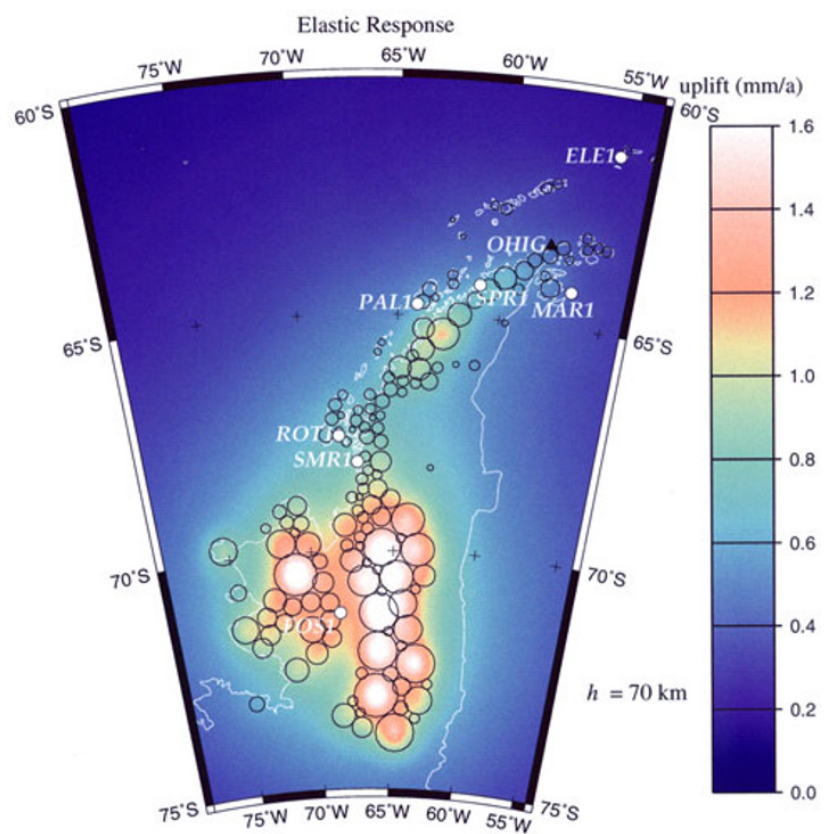

Fig. 3. Vertical motion due to present-day mass loss at rate $\dot{M}_{\mathrm{pd}}=-48$ $\mathrm{Gt} / \mathrm{yr}$ with elastic rheology. Unloading occurs on all 146 circular discs. The rate is equivalent to a regional imbalance of $6 \%$, corresponding to a $0.133 \mathrm{~mm} / \mathrm{yr}$ contribution to present-day sea level rise. The assumption of a purely elastic rheology means that the crustal motion is sensitive only to $\dot{M}_{\text {pd }}$ (see Eq. (1)). the Peninsula (Doake et al., 1998). Vaughan et al. (1999) recently determined that the Peninsula north of $75^{\circ} \mathrm{S}$ sustains an accumulation input of roughly $2390 \mathrm{Gt} / \mathrm{yr}$. Partitioning $1 / 3$ of this input to grounded ice and taking the imbalance (capable of contributing to a secular 20th Century sea level rise) to be $6 \%$, yields a value of $-48 \mathrm{Gt} / \mathrm{yr}$. We shall use this value for the mass imbalance of grounded ice in the Antarctic Peninsula in order to demonstrate how large present-day imbalances, and their associated isostatic disequilibrium, tradeoff with isostatic changes associated with earlier ice mass variability.

\subsection{Oscillatory load examples}

Figure 3 shows the present-day vertical uplift rate for the Antarctic Peninsula region using the disc-load distribution indicated in mapview. This calculation assumes a purely elastic response to the load shown in Fig. 4 with mass loss of $-48 \mathrm{Gt} / \mathrm{yr}$ at present-day. The discs vary only in height and not in radius. Note that the maximum uplift is coincident with the disc coverage, a feature which diminishes when the viscous response is accounted for. In spite of the substantial mass loss that is assumed (equivalent to a $0.133 \mathrm{~mm} / \mathrm{yr}$ contribution to secular sea level rise), this vertical response would be difficult to detect even under ideal conditions. For example, for a quasi-continuous time series having a scatter in

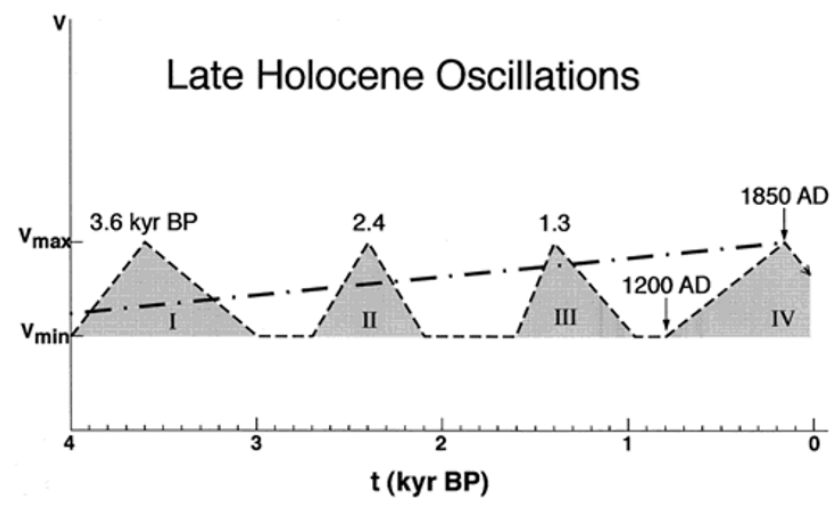

(a)

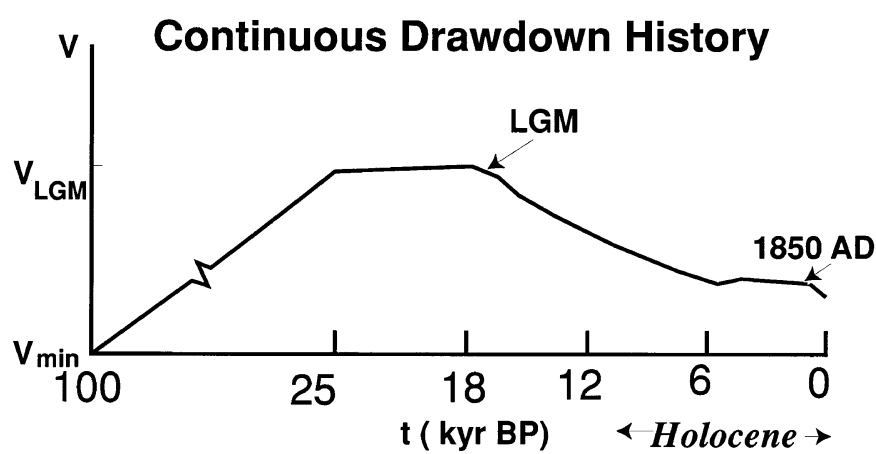

(b)

Fig. 4. Load (ice volume) for computations of Figs. 5, 6 and 7. All phases of frame a (dashed line) are included in the model for Fig. 5 $\left(V_{\max }-V_{\min }=5.65 \times 10^{4} \mathrm{~km}^{3}\right)$. A single phase with a 4500 year-long growth period is assumed in Fig. 6. (see dash-dot line of frame (a)). Frame (b) shows the load assumed for computations in Fig. 7. Post-1850 $\mathrm{AD}$ evolutions are identical. 
the vertical component identical to the average of two southern hemisphere IGS stations, Perth $\left(32^{\circ} \mathrm{S}\right)$ and Yarragadee $\left(29^{\circ} \mathrm{S}\right)$, of $9.4 \mathrm{~mm}$ (Herring, 1999), then GPS observations at the SCAR site FOS1 (see Fig. 1) would require 10 years of data in order for a linear trend to have an amplitude standout above the r.m.s. scatter in the vertical by more than $60 \%$.

If the solid earth rheology, however, involves ductile flow then predictions are altered substantially. For example, for a strength-depth profile similar to that of northern Europe, such that the mantle viscosity, $\eta$, is near $4 \times 10^{20} \mathrm{~Pa}$ s and the lithospheric thickness, $h$, is $70 \mathrm{~km}$ (Lambeck et al., 1998), then the expected signal increases 4 to 5-fold. Assuming the same present-day mass loss as in the purely elastic computation of Fig. 3, Fig. 5 shows the vertical rates for the same solid earth model as in Fig. 2, but now with the saw-toothed load of Fig. 4(a). For all of the oscillation model cases, a small LGM is approximated by a linearly increasing load on the discs shown in Fig. 5 from 108 to $14 \mathrm{kyr}$ BP followed by a linear unloading that is completed by $9 \mathrm{kyr} \mathrm{BP}$. The existence of this small volume LGM load (equivalent in size to each Holocene oscillation) has a negligible impact on the vertical rate predictions. Of interest in Fig. 5 is the phase-lagged behavior of the solid earth response: note that the sign of the vertical motion is reversed from that of the elastic response (Fig. 3). This is caused by the viscous memory of the 650year load buildup. As these phase lags may be critical for correctly interpretating solid earth geodetic signals driven by late-Holocene ice loading-unloading sequences, we are obliged to provide an analysis of the pertinent viscoelasticgravitational behavior. The basic physics is analogous to that of a dissipative mechanical system in forced oscillation.

\subsection{Single saw-tooth load}

Consider a single disc of radius $\alpha$ and a single saw-tooth load history which would include only two linear segments

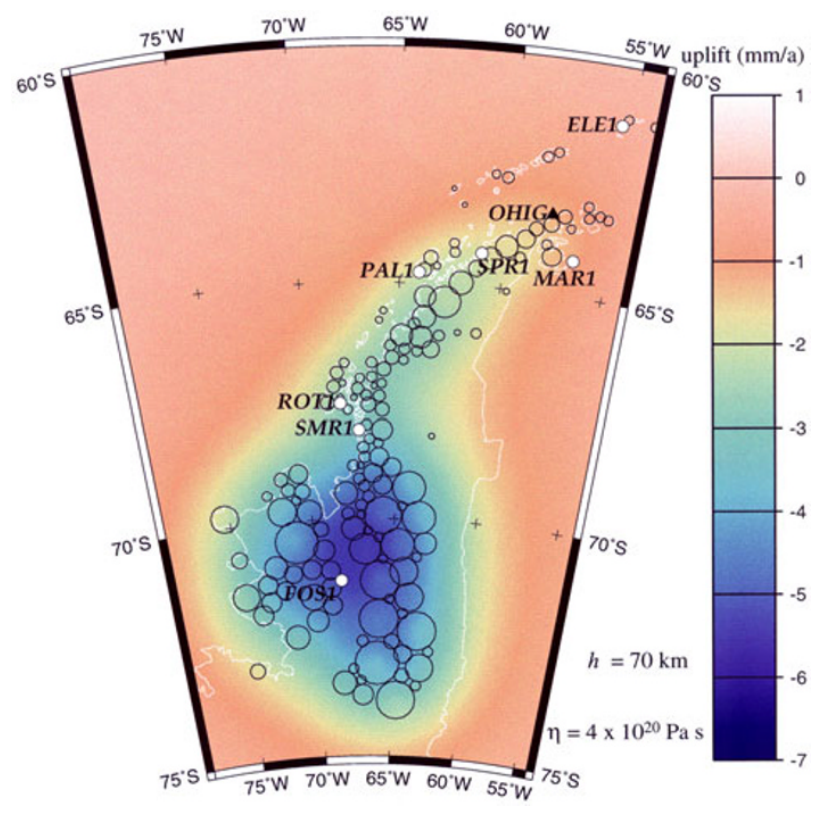

Fig. 5. Uplift rate predicted for multiple late-Holocene oscillations, the last having a growth phase duration of 650 years (see Fig. 4(a)). The rate of mass loss for the combined 146 discs since AD 1850 is identical in Figs. 3, 5, 6 and 7 . as in the dash-dot case of Fig. 4(a). For example, such a load could initiate at AD 1200, reach a maximum $\left(M_{\max }\right)$ at AD 1850 , and subsequently unload at a mass loss rate $\dot{M}_{\text {pd }}$ to the present-day. Analysis following Wolf (1985) and Ivins and James (1999) shows that the present-day vertical uplift rate is;

$$
\begin{aligned}
\dot{w}= & -\frac{g}{\pi \mu_{2}^{\mathrm{e}} \alpha} \cdot\left\langle\Gamma ^ { \prime } ( k ^ { \prime } ) \left\{\dot{M}_{\mathrm{pd}}\left[a_{2}^{\prime}\left(k^{\prime}\right)+\frac{\mu_{2}^{\mathrm{e}}}{4 k^{\prime} \mu_{1}^{\mathrm{e}}}\right]\right.\right. \\
& +v_{p}^{\prime}\left(k^{\prime}\right)\left\{\dot{M}_{\mathrm{pd}}\left[1-e^{-\gamma_{p}\left(k^{\prime}\right)\left(t-\Delta t_{1}\right)}\right]\right. \\
& \left.\left.\left.-\frac{M_{\max }}{\Delta t_{1}}\left(1-e^{\gamma_{p}\left(k^{\prime}\right) \Delta t_{1}}\right) \cdot e^{-\gamma_{p}\left(k^{\prime}\right) t}\right\}\right\}\right\rangle,
\end{aligned}
$$

with an implied sum over the two decay modes $(p)$. The convolution from wavenumber $\left(k^{\prime}\right)$ to radial position $r^{\prime}$ away from the disc center is

$$
\langle\cdots\rangle \equiv \int_{0}^{\infty} \cdots J_{0}\left(k^{\prime} r^{\prime}\right) J_{1}\left(k^{\prime} \alpha^{\prime}\right) d k^{\prime},
$$

with $J_{n}$ the Bessel functions of order $n$ and the prime indicating the scaling by $h$ as discussed by Ivins and James (1999). Here the final phase (post-1850 AD, see the youngest sawtooth portion of Fig. 4(a)) is of duration $\Delta t_{2}$ and the time at present-day is $t \equiv \Delta t_{1}+\Delta t_{2}$, with $\Delta t_{1}$ representing the duration of the assumed single growth phase. Equation (1) is a time-derivative of expression (36) of Ivins and James (1999) for the vertical displacement at the surface of a hydrostatically pre-stressed, two-layered gravitational half-space with the deepest layer of an incompressible Maxwell rheology with elastic shear modulus $\mu_{2}^{\mathrm{e}}$, density $\rho_{2}$ and viscosity $\eta$. The model top layer (lithosphere) has thickness $h$, shear modulus $\mu_{1}^{\mathrm{e}}$ and density of $\rho_{1}$. All of these layered earth parameters are implicitly retained in the amplitude factors $\Gamma^{\prime}\left(k^{\prime}\right)$ and $v_{p}^{\prime}\left(k^{\prime}\right)$ and the inverse decay times $\gamma_{p}\left(k^{\prime}\right)$. The explicit expressions are given in Ivins and James (1999), including that for $a_{2}^{\prime}\left(k^{\prime}\right)$. Equation (1) has a simple physical interpretation:

$$
\begin{aligned}
\dot{w}= & \text { Current Mass Balance Rate } \times(\text { Elastic Deformation } \\
& + \text { Viscous Memory of Most Recent Evolution }) \\
& +(\text { Most Recently Terminated Mass Balance Rate }) \\
& \times(\text { Viscous Memory Most Recently Terminated Change })
\end{aligned}
$$

Note the existence of two competing terms in parentheses. If the present-day rate of surface displacement is to be "inphase" with the present-day mass balance, then there must be sufficient time $\left(\Delta t_{2}\right)$ to generate a viscous memory of the "current" (i.e., interdecadal) linear evolution in ice mass. Both the ability to "remember" (or "forget") the earlier phase and to establish a sufficiently robust present-day viscous amplitude will be strongly viscosity-dependent. Additionally, there is a limit, $e^{-\gamma_{p}\left(k^{\prime}\right) \Delta t_{1}} \rightarrow 0$, in which the viscous memory of the growth phase $\left(\Delta t_{1}\right)$ saturates (see the last term on the right-hand-side of Eq. (1) and note that $\gamma_{p}\left(k^{\prime}\right)>0$, always). Physically, this means that sufficient time has elapsed for the load plus solid earth to have approached a new state of gravitational equilibrium. In Fig. 6 a single saw-tooth has been assumed for all discs representing the Antarctic Peninsula ice load with a relatively long growth phase of 4500 years and a viscosity of $0.9 \times 10^{20} \mathrm{~Pa} \mathrm{~s}$ and a thinner (40 $\mathrm{km}$ ) lithosphere than in the previous example (Fig. 5). Here, 


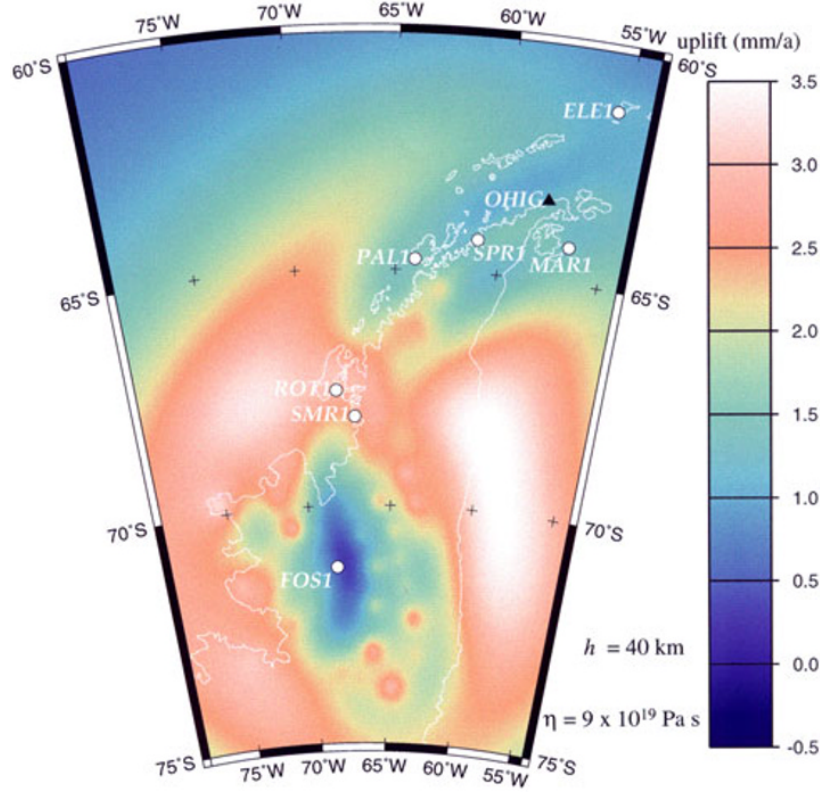

Fig. 6. Uplift rate predicted for a single oscillation having growth phase duration of $4500 \mathrm{yr}$ (see Fig. 4(a), dash-dot line). The combination of longer growth phase and lower viscosity (versus the oscillatory case of Fig. 5) allows isostatic equilibrium to be approached by 1850 AD. Post-1850 ice loss is identical to the cases shown in Figs. 2, 3 and 5.

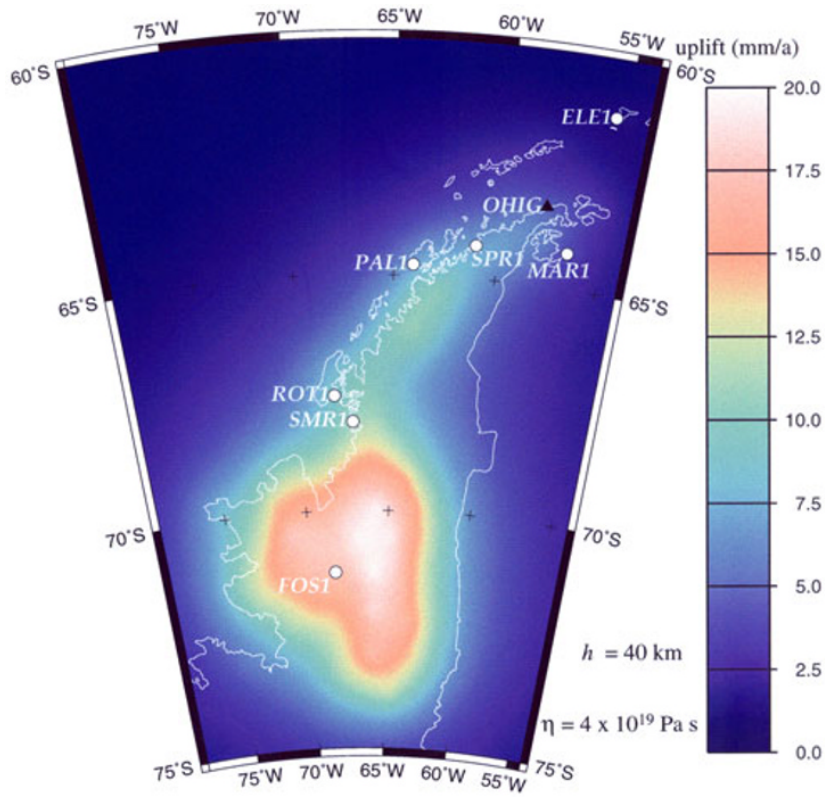

(a)

Fig. 7. Uplift rate prediction maps from non-oscillatory (continuous drawdown) deglaciation. The LGM load has a volume equivalent to $0.72 \mathrm{me}-$ ters of e.s.l.r., with approximately 0.26 meters eustatic equivalent since $11 \mathrm{kyr}$ BP. Disc positions are identical to those shown in Fig. 3. Note the stronger signature (by about $3 \times$ ) predicted by a mantle viscosity that is reduced by one order of magnitude and note the consistent uplift pattern, a feature which does not appear in the oscillatory load cases (contrast Figs. 5 and 6). The following volumetric evolution is assumed: 0 (108), 4.5 (25), 5.0 (18), 4.9 (17), 4.1 (15), 3.8 (13), 3.19 (11), 2.65 (9), 2.15 (8), $1.6(7), 1.3(6), 1.0(5.5), 1.1(5.0), 1.0(0.15)$, where the first value represents a factor $\times\left(V_{\max }-V_{\min }\right)$ and the second (in parentheses) is the corresponding time in kyr BP. The value of the volume difference, $V_{\max }-V_{\min }\left(=5.65 \times 10^{4} \mathrm{~km}^{3}\right)$, is identical to Figs. 5 and 6 .

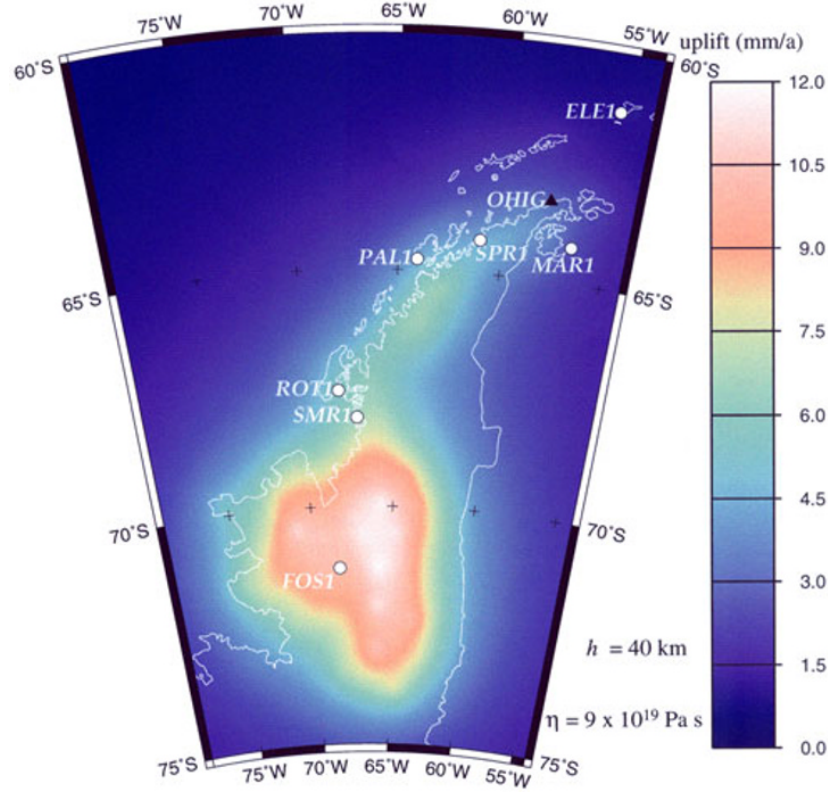

(b)

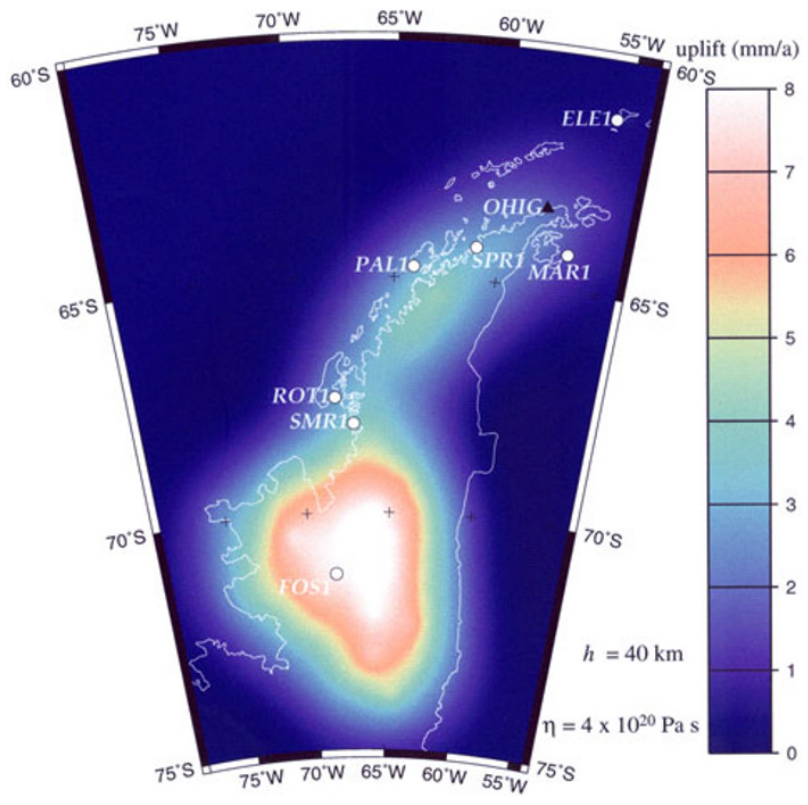

(c)

Fig. 7. (continued)

the overall decay times, $\gamma_{p}^{-1}$, and duration of growth phase, $\Delta t_{1}$, are sufficiently short and long, respectively, that the growth phase drives a deformation that approaches gravitational equilibrium and, thus, is less important to the prediction of present-day solid earth response signature. However, in this example, the explicit wavenumber $\left(k^{\prime}\right)$ dependence of the prediction is also revealed. Note that the maximum uplift rates occur in the longest wavelength patterns of the deformation field (Fig. 6), as these have the shortest decay times, $\gamma_{p}^{-1}$, since they are more sensitive to the viscous mantle and less sensitive to the elastic lithosphere. As the duration of the load growth phase is reduced from $4500 \mathrm{yr}$, the tendency to predict subsidence at present-day is enhanced, especially 
at the shorter wavelengths of the deformation field.

\subsection{Continuous drawdown load response}

Much of the current debate over Holocene Antarctic ice sheet evolution is focussed on how, or why, the continent-toocean mass transfer process that operated 10,000 years ago should abruptly terminate during mid- to late-Holocene time. For example, evidence for a continuous drawdown in the volume of the continent-based ice sheet into late-Holocene time, and which continues to the present-day, comes from recent ${ }^{14} \mathrm{C}$ chronological reconstruction of the ice sheet grounding line position over the past 6800 years in the Ross Sea (Conway et al., 1999). This deglaciation style may produce a distinctly different response character in comparison to either of the two examples of load evolution that we have discussed thus far in this paper. A difference between the continuous drawdown and the LGM response calculated for Fennoscandia (or any ice sheet ceaseing oceanic mass exchange at 7-9 kyr BP) is inherent to the viscoelasticity of rock that is continuously subjected to an ice load stress, $\sigma$. As long as the ice load stress, $\sigma$, is present, and acts with the same sign over time, it drives motion through the first two terms on the righthand-side of Eq. (1) (associated with $\dot{M}_{\text {pd }}$ ). Note here that as $t-\Delta t_{1}$ becomes large, the term, $1-e^{-\gamma_{p}\left(k^{\prime}\right)\left(t-\Delta t_{1}\right)}$, is maximized, so that present-day viscous response to present-day deglaciation is also maximized. Note that in the continuous drawdown case there is no cancellation with the terms that follow, as occurs in the case of oscillatory surface loading. All of the terms associated with older linear segments in the load representation contribute, ultimately, to $\dot{w}$ with the same sign in the continuous drawdown case.

To illustrate this fundamental difference in the vertical motion prediction between monotonic and oscillatory cases, we now explore a continuous drawdown of a late-Holocene load having the same disc structure as in Figs. 3, 5 and 6. The final linear segment in each of the oscillatory cases (i.e., since AD 1850) are identical in mass change. The drawdown case also contains an identical final segment. Although the load is unrealistic in the sense that it utilizes the same 146 discs throughout a simulated 108,000 year evolution, it serves the purposes of a systematic comparison to the oscillatory load cases. The assumed total volume change over the complete $100 \mathrm{kyr}$ glacial cycle is quite small; a mere 0.78 meters of e.s.l.r. and only an equivalent 0.5 meters since $11 \mathrm{kyr}$ BP. The explicit load history is shown in Fig. 4(b). The presentday response is predicted in Figs. 7(a)-(c) for three different mantle viscosity values, all other parameters being identical. Note the sensitivity to viscosity, with the $\eta=4 \times 10^{19}$ Pa s case (Fig. 7(a)) predicting more than double the uplift rates of the case of viscosity that is increased by one order of magnitude (Fig. 7(c)). However, even in the case of Fennoscandian-like viscosity $\eta=4 \times 10^{20} \mathrm{~Pa} \mathrm{~s}$ (Fig. 7(c)), the relatively small deglaciation $(<1 \mathrm{~m}$ of e.s.l.r.) predicts a surprisingly large uplift rate at the present-day. While this has been noted in previous calculations of Antarctic deglaciation, this is the first systematic study of alternative styles of late-Holocene ice mass change. Response to a continuous drawdown mode of deglaciation has important implications for geodetic observational strategies on solid bedrock due to the relatively large predicted signatures. Possibly as important is the fact that the continuous drawdown response is relatively uncomplicated by the stronger sensitivity to mantle viscosity, load sequencing and wavenumber-dependence that the oscillatory load cases exhibit.

\section{Conclusions}

In this paper we have examined three different types of ice load changes for the Antarctic Peninsula in order to predict present-day vertical rebound that could be measured using GPS. The three different load types are: (1) no evolution (constant ice mass) since $5.5 \mathrm{kyr}$ BP, but having a model for LGM ice mass that is consistent with the reconstructions by Payne et al. (1989) and Denton et al. (1991); (2) oscillatory evolution since $4.0 \mathrm{kyr}$ BP which includes a realistic (albeit large) mass change rate since the year AD 1850; and, finally; (3) a model having a small LGM buildup, but a continuous drawdown of ice mass with the final 150 years identical to case (2). The first case (1) is similar to the study of rebound wherein the time elapsed since deglaciation, size of the ice load, mantle viscosity and lithospheric thickness are the main parameters that influence the prediction of present-day uplift rate and pattern. A single mapview of one prediction is given in Fig. 2. In the second case, one must add the details of the last millennial to centennial-scale oscillation(s), including the duration of loading and unloading sequences and net volume exchange with the ocean to this list. If the mantle viscosity is in the range $10^{19}$ to $4 \times 10^{20} \mathrm{~Pa}$ s, then much of the wavenumber-dependent decay spectra for rebound is found at centennial and millennial time scales. Either present-day subsidence or uplift (see Figs. 5 and 6) are possible and the prediction is highly sensitive to mantle viscosity and lithospheric thickness. This complicates both the sense and pattern of predicted present-day crustal motion and the response is somewhat like a phase-lagged viscoelastic wave. In this case GPS arrays, or, at minimum, a linear profile of stations to obtain the spatial pattern of rebound is strongly recommended. In the final load case studied (continuous drawdown) the sense and patterns are consistent with the case (1) of postglacial rebound. What is more interesting, however, is that the uplift may be quite large across a range of reasonable mantle viscosity and lithospheric thickness values. GPS observation of robust vertical height changes, therefore, might be a key indicator of the continuous drawdown mode of deglaciation. Although this continuous mode might well operate in the Antarctic Peninsula region south of $69^{\circ} \mathrm{S}$, it may also apply to the Ross sector of the west Antarctic ice sheet as suggested recently by Conway et al. (1999).

Acknowledgments. We thank Patrick Wu for his comments on an early draft and also Kazuo Shibuya and Hans-Georg Scherneck for very helpful reviews. This work was performed at the Jet Propulsion Laboratory, California Institute of Technology and at the Pacific Geoscience Centre, an office of the Geological Survey of Canada. A grant from the Solid Earth and Natural Hazards Program of NASA's Earth Science Office has provided support for this research. Geological Survey of Canada Contribution 1999248.

\section{References}

Barker, P. F., The Cenozoic history of the Pacific margin of the Antarctic Peninsula: ridge crest trench interactions, J. Geol. Soc. Lond., 139, 787801,1982

Bell, A. C. and E. C. King, New seismic data support Cenozoic rifting in George VI Sound, Antarctic Peninsula, Geophys. J. Int., 134, 889-902, 
1998.

Bentley, M. J. and J. B. Anderson, Glacial and marine geological evidence for the ice sheet configuration in the Weddell Sea-Antarctic Peninsula region during the Last Glacial Maximum, Antarctic Sci., 10, 309-325, 1998.

Björck, S., S. Olsson, C. Ellis-Evans, H. Håkansson, O. Humlum, and J. M. de Lirio, Late Holocene paleoclimatic records from lake sediments on James Ross Island, Antarctica, Paleogeog. Paleoclimatology, Paleoecology, 121, 195-220, 1996.

Clapperton, C. M., Quaternary glaciations in the Southern Ocean and Antarctic Peninsula area, Quat. Sci. Rev., 9, 229-252, 1990.

Clapperton, C. M. and D. E. Sugden, Holocene glacier fluctuations in South America and Antarctica, Quat. Sci. Rev., 7, 185-198, 1988.

Conway, H., B. L. Hall, G. H. Denton, A. M. Gades, and E. D. Waddington, Past and future grounding-line retreat of the West Antarctic ice sheet, Science, 286, 280-283, 1999.

Cullather, R. I., D. H. Bromwich, and M. L. Van Woert, Spatial and temporal variability of Antarctic precipitation from atmospheric methods, $J$. Climate, 11, 334-367, 1998.

Dietrich, R., R. Dach, G. Engelhardt, J. Ihde, W. Korth, H.-J. Kutterer, K. Lindner, M. Mayer, F. Menge, H. Miller, W. Niemeier, J. Perlt, M. Pohl, H. Salbach, H.-W. Schenke, T. Schöne, G. Seeber, A. Veit, and C. Völksen, ITRF coordinates and plate velocities from repeated GPS campaigns in Antarctica - an analysis based on different individual solutions, $J$. Geodesy, 2001 (in press).

Denton, G. H., M. L. Prentice, and L. H. Burckle, Cainozoic history of the Antarctic ice sheet, in Geology of Antarctica, edited by R. J. Tingey, pp. 365-433, Oxford Univ. Press, Clarendon, Oxford, 1991.

Drewry, D. J. and E. M. Morris, The response of large ice sheets to climate change, Phil. Trans. R. Soc. London, Ser. B, 338, 235-242, 1992.

Doake, C. S. M., H. F. J. Corr, H. Rott, P. Skvarca, and N. W. Young, Breakup and conditions for stability of the northern Larsen Ice Shelf, Antarctica, Nature, 391, 778-780, 1998.

Genthon, C. and G. Krinner, Convergence and disposal of energy and moisture on the Antarctic polar cap from ECMWF reanalysis and forecasts, J. Climate, 11, 1703-1716, 1998.

Herring, T. A., Geodetic applications of GPS, Proc. I.E.E.E., 87, 92-110, 1999.

Hole, M. J., G. Rogers, A. D. Saunders, and M. Storey, Relation between alkalic volcanism and slab window formation, Geology, 19, 657-660, 1991.

Ingólfsson, Ó., C. Hort, P. A. Berkman, S. Björck, E. Calhoun, I. Goodwin, B. Hall, K. Hirakawa, M. Melles, P. Moller, and M. L. Prentice, Antarctic glacial history since the Last Glacial Maximum: an overview of the record on land, Antarctic Sci., 10, 326-344, 1998.

Ivins, E. R. and T. S. James, Simple models for late-Holocene and presentday Patagonian glacier fluctuation and predictions of a geodetically detectable isostatic response, Geophys. J. Int., 131, 601-624, 1999.
James, T. S. and E. R. Ivins, Predictions of Antarctic crustal motions driven by present-day ice sheet evolution and by isostatic memory of the Last Glacial Maximum, J. Geophys. Res., 103, 4993-5017, 1998.

James, T. S., J. J. Clague, K. Wang, and I. Hutchinson, Postglacial rebound at the northern Cascadia subduction zone, Quat. Sci. Rev., 19, 1527-1541, 2000 .

Jòhannesson, T., C. Raymond, and E. Waddington, Time-scale for adjustment of glaciers to changes in mass balance, J. Glaciology, 35, 355-369, 1989.

Lambeck, K., C. Smither, and P. Johnston, Sea-level change, glacial rebound and mantle viscosity for northern Europe, Geophys. J. Int., 134, 102-144, 1998.

Okuno, J. and M. Nakada, Rheological structure of the upper mantle inferred from the Holocene sea-level change along the west coast of Kyushu, Japan, in Dynamics of the Ice Age Earth: A Modern Perspective, edited by P. Wu, pp. 443-458, Trans Tech Pub., Uetikon-Zürich, Switzerland, 1998.

Payne, A. J., D. E. Sugden, and C. M. Clapperton, Modeling the growth and decay of the Antarctic Peninsula Ice Sheet, Quaternary Res., 31, 119-134, 1989.

Peltier, W. R., Ice age paleotopography, Science, 265, 195-201, 1994.

Raymond, C. A., M. B. Heflin, E. R. Ivins, and T. S. James, Modern uplift of the Transantarctic mountains: Preliminary results of an autonomous GPS array, 8th Int. Symp. Antarctic Earth Sci., July 5-9, 1999, Victoria University of Wellington, New Zealand (abs.), 1999.

Scarrow, J. H., P. T. Leat, C. D. Wareham, and I. L. Millar, Geochemistry of mafic dykes in the Antarctic Peninsula continental-margin batholith: a record of arc evolution, Contrib. Mineral. Petrol., 131, 289-305, 1998.

Scherneck, H.-G., J. M. Johansson, J. X. Mitrovica, and J. L. Davis, The BIFROST project: GPS determined 3-D displacement rates in Fennoscandia from 800 days of continuous observations in the SWEPOS network, Tectonophys., 294, 305-321, 1998.

Studinger, M. and H. Miller, Crustal structure of the Filchner-Ronne shelf and Coats Land, Antarctica, from gravity and magnetic data: implications for the breakup of Gondwana, J. Geophys. Res., 104, 20,379-20,394, 1999.

Tregoning, P., B. Twilley, M. Hendy, and D. Zwartz, Monitoring isostatic rebound in Antarctica using continuous remote GPS observation, GPS Solutions, 2, 70-75, 1999.

Vaughan, D. G., J. L. Bamber, M. Giovinetto, J. Russell, and A. P. R. Cooper, Reassessment of net surface mass balance in Antarctica, J. Climate, 12, 933-946, 1999.

Wolf, D., The normal modes of a layered, incompressible Maxwell halfspace, J. Geophys., 57, 106-117, 1985.

E. R. Ivins (e-mail: eri@fryxell.jpl.nasa.gov), C. A. Raymond, and T. S. James 